\title{
Mechanical Properties of Poly(L-Lactide) Films Controlled by Blending with Polyesters of Lignin-Derived Stable Metabolic Intermediate, 2-Pyrone-4,6-Dicarboxylic Acid (PDC)
}

\author{
By Tsuyoshi MiChINOBU,,$^{1,2, \dagger}$ Masami BITo, ${ }^{1}$ Miki TANIMURA, ${ }^{1}$ Yoshihiro KATAYAMA, ${ }^{3}$ Eiji MASAI ${ }^{4}$ \\ Masaya NAKAMURA, ${ }^{5}$ Yuichiro OTSUKA, ${ }^{5}$ Seiji OHARA, ${ }^{5}$ and Kiyotaka SHIGEHARA ${ }^{1,2, *}$
}

Two kinds of polyesters containing 2-pyrone-4,6-dicarboxylic acid (PDC) moieties in poly(L-lactic acid) (PLLA) and poly(butylene succinate) (PBS) main chains were for the first time employed as an additive to PLLA for improvement of the mechanical properties. Solution casting of a mixture of PLLA and PDC polyesters provided the blend films, which were comprehensively characterized by thermal analyses, tensile measurements, and crystallinity evaluation. Differential scanning calorimetry measurements revealed that PDC incorporation into polymer main chain dramatically improves the miscibility with PLLA. PDC-incorporated PBS showed better miscibility than PDC-incorporated PLLA. Optical microscopy measurements also suggested the superior orientation of PDC-incorporated PBS over PDC-incorporated PLLA in the blend films. The fracture strain of the blend films could be linearly increased by a draw ratio in the region of low PDC polyester content. On the contrary, the fracture strain decreased at high PDC polyester content due to the restricted strain caused by the strong dipolar interactions between PDC moieties. Elongation at break was significantly varied as a function of PDC polyester content, whereas tensile modulus was almost independent of the additive content and draw ratios. It is concluded that the blend films containing $<10 \mathrm{wt} \%$ of PDC-incorporated PBS as an additive show the best tensile property.

KEY WORDS: Biomass / Lignin / Mechanical Strength / Polyester / Polylactide /

Poly(L-lactic acid) (PLLA) is one of the most promising biomass-based polymers for construction of "carbon-neutral" sustainable society. ${ }^{1-8}$ Because of the biodegradability and nontoxicity to the environment and human body, it has been widely used in biomedical applications, but the poor thermal and mechanical properties of PLLA have hindered other applications such as engineering plastics. In order to improve these poor properties and expand the application possibilities of PLLA, blending with thermally and mechanically stronger molecules $^{9-11}$ and polymers ${ }^{12-24}$ is often employed. However, since there are not many appropriate additives that are miscible with PLLA, little success has been achieved.

We previously established the massive production protocol of a small pseudo-aromatic ring molecule, 2-pyrone-4,6dicarboxylic acid (PDC), from the lignin-bio-metabolic intermediates by transformed bacterium. ${ }^{25}$ By using this molecule as a bifunctional monomer for polycondensation and polyaddition, we have succeeded in the preparation of several biopolymers containing PDC nuclei in the main chain. ${ }^{26-28}$ For example, incorporation of PDC moieties into poly(ethylene terephthalate) (PET) improved the thermal and adhering properties of the resulting polyesters. ${ }^{29}$ Similarly, the PDC- incorporated poly(butylene succinate) (PBS) showed a remarkable increase in the biodegradability. ${ }^{30}$ Copolyesters of PDC and L-lactic acid also displayed the comparable thermal properties to PLLA. ${ }^{31}$ All these studies revealed that the excellent properties of PDC are retained after the copolymerization and that the polymer properties can be tunable by a variation of PDC content. It should be noted that PDC has never been prepared from petrochemical sources. ${ }^{32-34}$ Therefore, other advantageous features of the copolymers have not yet been clarified completely.

In order to exploit a new use of the PDC copolymers, we became interested in the employment as a blend material with PLLA. In view of the maintenance of high biomass content and miscibility with PLLA, the PDC-incorporated PLLA and PBS were selected (Scheme 1). They are biomassbased copolyesters with improved thermal stability and biodegradability. Herein, we for the first time report the comprehensive studies of the blend films of PLLA and PDC copolymers by thermal analysis, tensile measurements, and X-ray diffraction analysis. For comparison, the blend film of PLLA and PBS was also prepared and their corresponding properties are described.

\footnotetext{
${ }^{1}$ Graduate School of Engineering, Tokyo University of Agriculture and Technology, Koganei 184-8588, Japan

${ }^{2}$ Institute of Symbiotic Science and Technology, Tokyo University of Agriculture and Technology, Koganei 184-8588, Japan

${ }^{3}$ Graduate School of Bio-Applications and Systems Engineering, Tokyo University of Agriculture and Technology, Koganei 184-8588, Japan

${ }^{4}$ Department of Bioengineering, Nagaoka University of Technology, Nagaoka 940-2188, Japan

5 Forestry and Forest Products Research Institute, Tsukuba 305-8687, Japan

'Present address: Global Edge Institute, Tokyo Institute of Technology, Ookayama, Meguro-ku, Tokyo 152-8550, Japan

*To whom correspondence should be addressed (Tel: +81-42-388-7052, Fax: +81-42-381-8175, E-mail: jun@cc.tuat.ac.jp).
} 


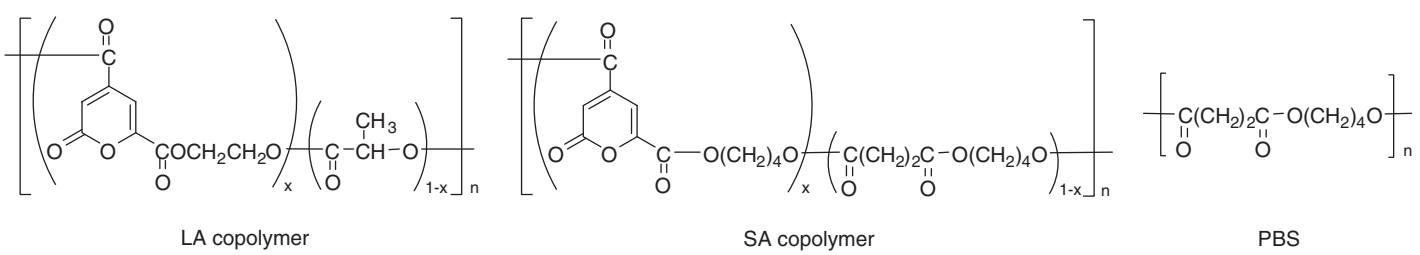

Scheme 1. Chemical structures of LA copolymer, SA copolymer, and PBS.

\section{EXPERIMENTAL}

\section{Materials}

All reagents were purchased from Kanto Chemical Co., Wako Chemical Co., and Tokyo Kasei Co., and used without further purification. Poly(L-lactic acid) (PLLA) was kindly supplied from Unitika Co. Ltd. (pure PLLA used in Terramac ${ }^{\circledR}$, $M_{\mathrm{n}}=1.74 \times 10^{5}$ with L-content of $>98 \%$ ). Polyesters of 2 pyrone-4,6-dicarboxylic acid (PDC) were prepared by polycondensation of either L-lactic acid (LA), PDC, and bis(2hydroxyethyl) 2-pyrone-4,6-dicarboxylate (BHPDC) ${ }^{31}$ or 1,4butanediol (1,4-BD), succinic anhydride (SA), and PDC. ${ }^{30}$ The former copolymer is symbolized as LA copolymer and the latter as SA copolymer.

Poly(butylene succinate) (PBS) was prepared by polycondensation of 1,4-butanediol and succinic anhydride in the presence of $\mathrm{Sb}_{2} \mathrm{O}_{3}$ as a catalyst. A mixture of two monomers and a catalyst was charged in a round-bottle flask, and it was vigorously stirred at $170{ }^{\circ} \mathrm{C}$ under $\mathrm{N}_{2}$ for $7 \mathrm{~h}$ to afford the corresponding oligomers. The subsequent post-polymerization was performed at $170^{\circ} \mathrm{C}$ at $5 \mathrm{mmHg}$ for $17 \mathrm{~h}$ and then at $120^{\circ} \mathrm{C}$ at $5 \mathrm{mmHg}$ for $17 \mathrm{~h}$. After cooling to room temperature, chloroform was added to the reaction mixture and poured into methanol. The precipitates were collected and purified by reprecipitation from chloroform solution into methanol.

$M_{\mathrm{n}}\left(\mathrm{GPC}, \mathrm{CHCl}_{3}\right): 15000$.

${ }^{1} \mathrm{H}$ NMR $\left(\mathrm{CDCl}_{3}, 300 \mathrm{MHz}, 20{ }^{\circ} \mathrm{C}\right): \delta 1.64-1.73\left(-\mathrm{OCH}_{2} \mathrm{CH}_{2}-\right.$ $\left.\mathrm{CH}_{2} \mathrm{CH}_{2} \mathrm{O}-\right)$, 2.55-2.69 (-OC(=O) $\left.\mathrm{CH}_{2} \mathrm{CH}_{2} \mathrm{C}(=\mathrm{O}) \mathrm{O}-\right)$, 4.09$4.11\left(-\mathrm{OCH}_{2} \mathrm{CH}_{2} \mathrm{CH}_{2} \mathrm{CH}_{2} \mathrm{O}-\right)$ ppm.

${ }^{13} \mathrm{C} \mathrm{NMR}\left(\mathrm{CDCl}_{3}, 75 \mathrm{MHz}, 20{ }^{\circ} \mathrm{C}\right): \delta 25.2\left(-\mathrm{OCH}_{2} \underline{\mathrm{CH}}_{2} \underline{\mathrm{CH}}_{2}-\right.$ $\left.\mathrm{CH}_{2} \mathrm{O}-\right), 29.1$ (-OC(=O) $\left.\underline{\mathrm{CH}}_{2} \mathrm{CH}_{2} \mathrm{C}(=\mathrm{O}) \mathrm{O}-\right)$, $64.2\left(-\mathrm{OCH}_{2} \mathrm{CH}_{2}-\right.$ $\left.\mathrm{CH}_{2} \mathrm{CH}_{2} \mathrm{O}-\right), 172.3$ (-OC( $\left.\left.(=\mathrm{O}) \mathrm{CH}_{2} \mathrm{CH}_{2} \underline{\mathrm{C}}(=\mathrm{O}) \mathrm{O}-\right)\right)$ ppm.

IR (liquid film): v 2946, 2359, 2342, 1714, 1558, 1472, 1447, 1426, 1388, 1338, 1313, 1162, 1047, 956, 919, 807, 754, 668, $453,407 \mathrm{~cm}^{-1}$.

\section{Blend Polymers and Film Preparation}

Chloroform was added to PLLA and the PDC polyesters or to PLLA and PBS. The ratio of the PDC polyesters and PBS ranges from 0 to $20 \mathrm{wt} \%$. After the mixture was vigorously stirred, the solvent was evaporated in vacuo and dried at room temperature. The obtained solid samples were employed for thermal analysis. The blended solids were dissolved in chloroform again and cast on Petri dishes, and the solvent was allowed to evaporate at room temperature. The obtained films were further dried in vacuo to remove the residual solvent.
Then, they were cut into a certain size $(5 \times 5 \mathrm{~mm}, 0.02-$ $0.07 \mathrm{~mm}$ thickness) and drawn by 3,4 , and 5 times at $50^{\circ} \mathrm{C}$ at a rate of $5 \mathrm{~mm} \mathrm{~min}^{-1}$ with a load of $5 \mathrm{kgf}$ using a film-stretching machine. The original and drawn blend films were employed for the measurements of the mechanical properties, wide-angle $\mathrm{X}$-ray diffraction, and optical microscopy images.

\section{Measurements}

${ }^{1} \mathrm{H}$ NMR and ${ }^{13} \mathrm{C}$ NMR spectra were measured on a JEOL model AL300 spectrometer at $20^{\circ} \mathrm{C}$. Chemical shifts of PBS are reported in ppm downfield from $\mathrm{SiMe}_{4}$, using the solvent's residual signal as an internal reference. Infrared (IR) spectra were recorded on a JASCO FT/IR-4100 spectrometer. Number average molecular weights $\left(M_{\mathrm{n}}\right)$ of the polyesters were estimated by a JASCO 980 Gel Permeation Chromatography, calibrated by polystyrene standards.

Thermogravimetric analyses (TGA) and differential scanning calorimetry (DSC) measurements were carried out on a Rigaku Thermo plus TG8120 and DSC8230, respectively, under nitrogen flow, at a heating rate of $10^{\circ} \mathrm{C} \mathrm{min}^{-1}$ from $20^{\circ} \mathrm{C}$ to $500{ }^{\circ} \mathrm{C}$ for TGA and from $-50^{\circ} \mathrm{C}$ to $200^{\circ} \mathrm{C}$ for DSC. Strain-stress (S-S) curves of the blend films were measured at $20 \pm 2{ }^{\circ} \mathrm{C}$ in an atmosphere of dry nitrogen by using a Tensilon testing machine (Auto COM/AC-50A, TS Engineering Co.). Young's moduli or tensile moduli were estimated from the initial (less than $0.5 \%$ elongation) slopes of S-S curves. Optical microscopy images were taken with an Olympus BX51 optical microscopy. X-Ray diffraction patterns were measured by using a Rigaku X-ray diffractometer RU-200A. Degree of crystallinity $\left(\chi_{c}\right)$ of the blend films was calculated as an index of crystallinity from the reflection intensity of crystalline part $\left(I_{\mathrm{c}}\right)$ and the hollow intensity of amorphous part $\left(I_{\mathrm{a}}\right)$, according to Natta's method for polypropylene. ${ }^{35}$

$$
\chi_{\mathrm{c}}=I_{\mathrm{c}} /\left(I_{\mathrm{c}}+I_{\mathrm{a}}\right)
$$

\section{RESULTS AND DISCUSSION}

\section{Blend Film Preparation}

The molecular weight $\left(M_{\mathrm{n}}\right)$ and the PDC content of the polyesters employed as an additive to poly(L-lactic acid) (PLLA) are summarized in Table I. Blend films of PLLA and the PDC polyesters were prepared by slow evaporation of the chloroform solution on a Petri dish. Other methods such as hot press of the molten mixtures of PLLA and the PDC polyesters did not give a tough film because of the phase separation or bubble formation. 
Table I. Properties of the polyesters employed as an additive

\begin{tabular}{ccc}
\hline (co)polyester & $M_{\mathrm{n}}{ }^{\mathrm{a}}$ & PDC content $(\mathrm{mol} \%)^{\mathrm{b}}$ \\
\hline LA copolymer & 23300 & 1.5 \\
SA copolymer & 16000 & 2.8 \\
PBS & 15000 & 0 \\
\hline
\end{tabular}

aDetermined by GPC (polystyrene gel, $\mathrm{CHCl}_{3}$ eluent). ${ }^{\mathrm{b}}$ Determined by elemental analysis.

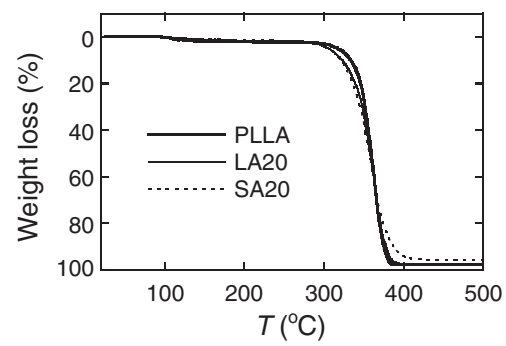

Figure 1. Thermogravimetric analysis of PLLA and the blend films LA20 (20 wt \% of LA copolymer) and SA20 (20 wt \% of SA copolymer) at a heating rate of $10^{\circ} \mathrm{C} \mathrm{min}^{-1}$ under $\mathrm{N}_{2}$.

First, thermal properties of the blend films were investigated. LA20 and SA20 represent the blend films composed of $80 \mathrm{wt} \%$ of PLLA and $20 \mathrm{wt} \%$ of LA copolymer and SA copolymer, respectively. Figure 1 shows the thermogravimetric analysis (TGA) curves of the blend films. PLLA is thermally stable up to about $300^{\circ} \mathrm{C}$ without any weight loss. The blend films, LA20 and SA20, started to decompose at slightly lower temperature than PLLA. However, their thermal stability was definitely higher than the original PDC polyesters, which usually start to decompose at about $250{ }^{\circ} \mathrm{C}$, reflecting the decomposition temperature of PDC moiety. ${ }^{36}$

The differential scanning calorimetry (DSC) thermograms of the blend films with different compositions are shown in Figure 2. PLLA displays an exothermic peak at $100-120^{\circ} \mathrm{C}$, indicating the crystallization in the heating scan. The subsequently emerging endothermic peak at about $170{ }^{\circ} \mathrm{C}$ is derived from the melting of PLLA crystals. In the blend films LA10 and LA20 (10 and $20 \mathrm{wt} \%$ of LA copolymer, respectively), the DSC curves were almost the same as that of PLLA (Figure 2a). The blend film SA10 also displayed the similar DSC curve, whereas SA20 exhibited a broad weak melting peak of SA copolymer (Figure 2b). In contrast, the blend film of PLLA and PBS, prepared for comparison with SA copolymer, showed a well-defined melting peak derived from PBS at about $103{ }^{\circ} \mathrm{C}$ (Figure 2c). These results indicate the high miscibility of the PDC polyesters with PLLA at least up to $20 \mathrm{wt} \%$. Miscibility of the additive polymers increases in the order of PBS $<$ SA copolymer $<$ LA copolymer.

\section{Mechanical Properties}

The blend films of about $0.02-0.07 \mathrm{~mm}$ thickness were cut into about $5 \times 5 \mathrm{~mm}$ blades and were subjected to the strainstress (S-S) measurements by a Tensilon testing machine in dry
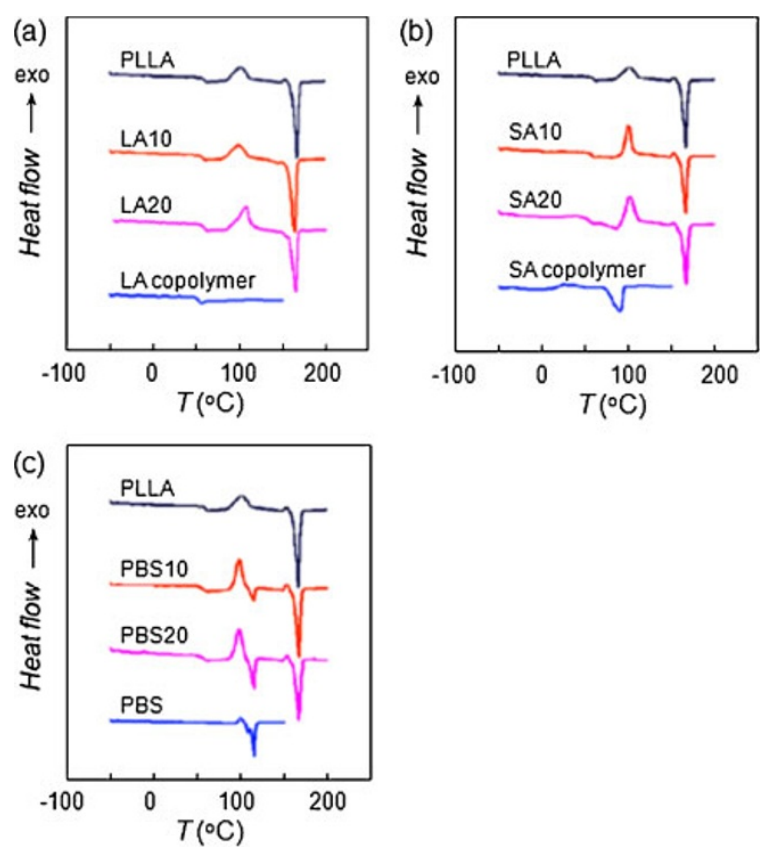

Figure 2. DSC curves (2nd heating scan) of PLLA, additive polymers, and the blend films at a scanning rate of $10^{\circ} \mathrm{C} \mathrm{min}^{-1}$ under $\mathrm{N}_{2}$.

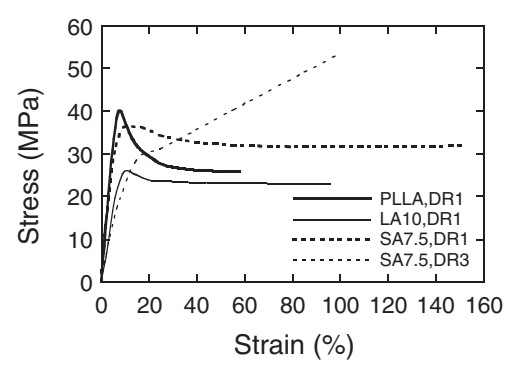

Figure 3. Strain-stress curves of PLLA and the blend films of PDC polyesters at different draw ratios.

nitrogen at $20 \pm 2{ }^{\circ} \mathrm{C}$. Since it is reported that the mechanical properties of PLLA is dependent on a draw ratio (DR), ${ }^{37}$ several samples with different draw ratios of 1, 3, 4, and 5 were prepared for each blend film. When the blend films were drawn at $60^{\circ} \mathrm{C}$, the glass transition temperature of PLLA, the films were often fractured. After several attempts at different temperatures, the appropriate drawn temperature was found to be $50^{\circ} \mathrm{C}$. Figure 3 depicts some examples of the typical S-S curves of PLLA and the blend films, LA10 and SA7.5, at different draw ratios. Both PLLA and the blend films showed the yield point at the strain of about $7-9 \%$ with the maximum stress of 25-40 MPa. Beyond the yield points, the blend films showed further ductility up to the strain of about $100 \%$ for LA10 and $150 \%$ for SA7.5 with the almost constant stress, reflecting the viscoelastic properties. When SA7.5 was drawn by 3 times, the yield point disappeared and the maximum stress at break increased to about $50 \mathrm{MPa}$. Thus, mechanical properties of PLLA blend films largely depend on the blend materials and the draw ratio. 
(A)
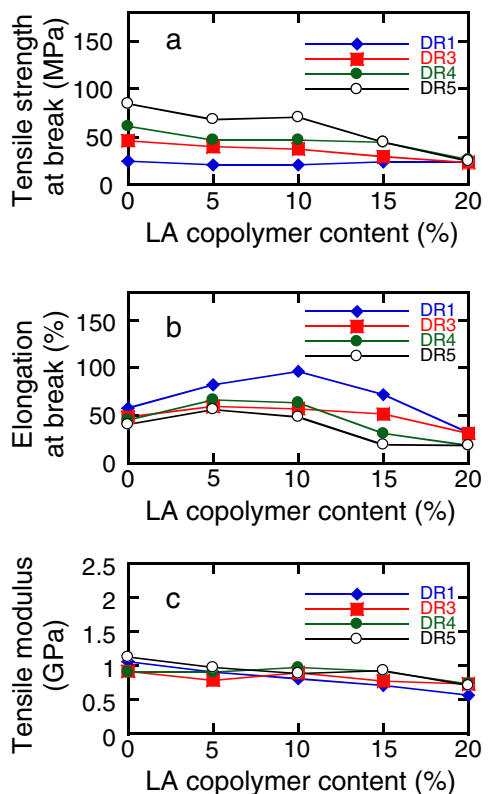

(B)
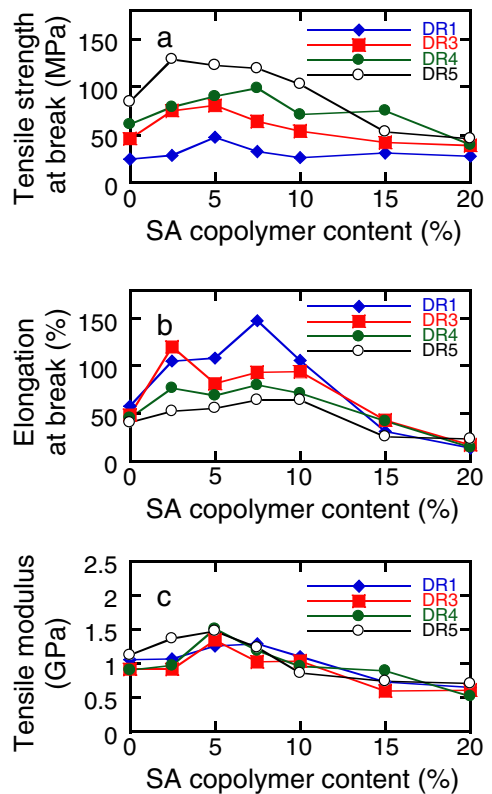

(C)

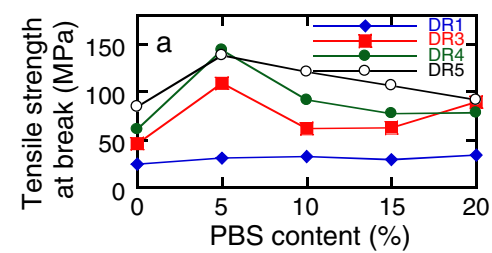

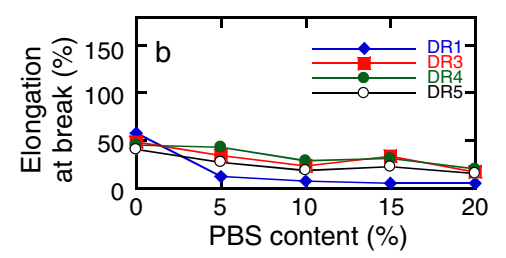

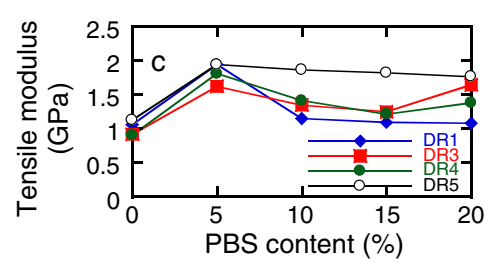

Figure 4. Relationship between the mechanical properties of PLLA blend films and the content of the additives: (A) LA copolymer, (B) SA copolymer, and (C) PBS.

It is reported that the tensile strength at break of PLLA linearly increases with a draw ratio. ${ }^{37}$ This is also true for the blend films when the PDC polyester content is less than $10 \mathrm{wt} \%$. For example, the blend films of LA copolymer showed the almost linear relationship in the range of LA copolymer content of 1-10 wt \% (Figure 4(A)a). However, the tensile strength at break of the film with DR $=5$ significantly decreased when the LA copolymer content exceeded $15 \mathrm{wt} \%$. In the case of the blend films of SA copolymer, a similar trend was observed. The tensile strength at break showed the maximum value at the SA copolymer content of 2.5$7.5 \mathrm{wt} \%$, and the highest value was $128 \mathrm{MPa}$ for the film with $\mathrm{DR}=5$ (Figure 4(B)a). Since the same behavior was also observed for the blend films of PBS, a succinic polyester is supposed to significantly contribute to the enhancement of the tensile strength in the region of a low additive content. The films with $\mathrm{DR}=1$ showed the almost constant tensile strength irrespective of the additive species and content, whereas the tensile strength always decreased in the region of a high additive content for the drawn samples.

PLLA without additives is reported to show a maximum value of elongation at break at $\mathrm{DR}=2 .{ }^{37}$ However, in this study, the maximum value of elongation at break was observed at $\mathrm{DR}=1$. The ductility at $\mathrm{DR}=1$ displayed the maximum value at the PDC polyester content of 7.5-10 wt \% (Figure 4(A)b and 4(B)b). The drawn blend films of PDC polyesters also exhibited a similar trend, but the change in the elongation became negligible as an increase in the draw ratio. The difference in the blend films between LA copolymer and SA copolymer might reflect the PDC content in the additive polymers. The blend film of SA copolymer (7.5 wt \%) showed the largest elongation of $148 \%$ at $\mathrm{DR}=1$. Remarkably, this result is in sharp contrast to the blend films of PBS. With the increasing amount of PBS content in the blend films, the ductility gradually decreased (Figure $4(\mathrm{C})$ b). A small amount of polar PDC nuclei integrated into the succinic polyester was supposed to effectively interact with each other even in the dispersed blend films, leading to the good tensile properties. However, when the density of PDC moiety is too high, the restricted strain in the polymer blend networks would result in the brittleness of the films. In other words, the intermolecular dipolar interactions of PDC moieties, as revealed by the crystal structures of PDC, ${ }^{36}$ are in competition with the van der Waals interactions of PLLA and the blending polyesters. This relationship is also regarded as an important factor in optimizing the adhesive properties of the PDC polymers. ${ }^{29}$

From the initial slope of S-S curves, tensile moduli of the blend films were roughly estimated. The rigid and brittle nature of PBS blend films was characterized by the high tensile moduli as compared to the blend films of PDC polyesters. The tensile moduli were almost independent of the draw ratio, but the maximum value was obtained at the additive polymer content of $5 \mathrm{wt} \%$ for the blend films of SA copolymer and PBS (Figure $4(\mathrm{~B}) \mathrm{c}$ and $4(\mathrm{C}) \mathrm{c})$. The tensile modulus of the blend films of LA copolymer slightly decreased with the increasing amount of LA copolymer (Figure 4(A)c).

\section{Degree of Crystallinity}

Since the mechanical properties are mainly reflected by molecular orientations in the solid state, the degree of crystallinity induced by drawing was investigated for each blend film by X-ray diffraction (XRD). As an example, the 
(a)

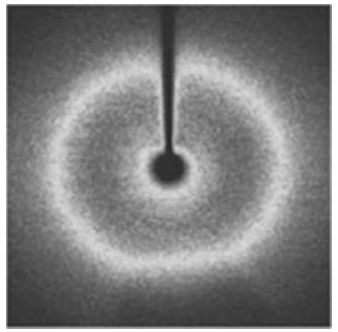

(b)

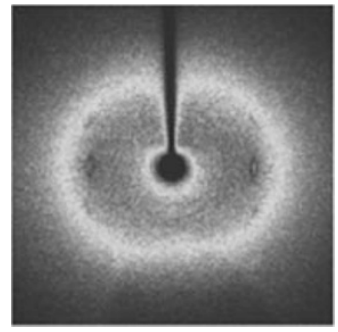

Figure 5. XRD patterns of PLLA film at a draw ratio of (a) 1 and (b) 5 .

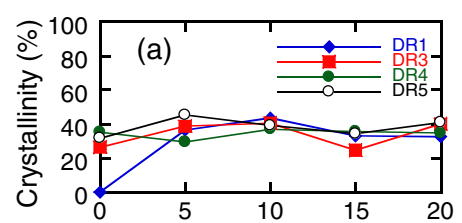

LA copolymer content (\%)
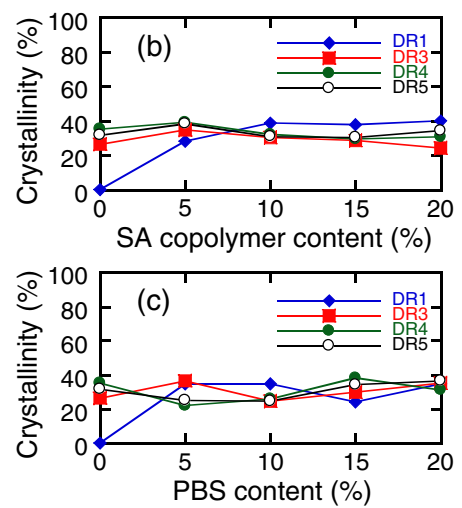

Figure 6. Relationship between the crystallinity of PLLA blend films and the content of the additives: (a) LA copolymer, (b) SA copolymer, and (c) PBS.
XRD patterns of PLLA at DR $=1$ and $D R=5$ are shown in Figure 5. PLLA at $\mathrm{DR}=1$ or without drawing showed a typical isotropic peak profile, whereas PLLA at DR $=5$ displayed a characteristic diffraction peak of partial orientations. The degree of crystallinity calculated according to Natta's method ${ }^{35}$ was $31.7 \%$. PBS is known to be more crystalline than PLLA. Addition of $5 \mathrm{wt} \%$ of PBS into PLLA increased the degree of crystallinity to $34.6 \%$ without any drawing, but the subsequent drawing did not improve the degree of crystallinity in this case (Figure 6c). Similarly to the relationship between PBS and PLLA, SA copolymer is supposed to be more crystalline than LA copolymer. However, the degree of crystallinity estimated for each blend film was almost constant within experimental errors, regardless of the additive content and draw ratio (Figure 6a and 6b). Thus, effects of different polymer additives and draw ratios were not apparent in the XRD experiments.

In order to elucidate the difference in the molecular orientation, the sample blades were subjected to optical microscopy measurements. Figure 7 shows the optical microscopy images of the blend films of $10 \mathrm{wt} \%$ of the additives with different draw ratios. The blend films of LA copolymer and SA copolymer were transparent, whereas that of PBS was a slightly turbid film, reflecting the partial phase separation due to the poor miscibility of PLLA and PBS. This result is consistent with the DSC thermograms of the blend films (vide supra). Incorporation of a small amount of PDC nuclei (merely $2.8 \%$ ) into the polymer main chain could improve the miscibility of succinic polyesters with PLLA. After drawing at $50{ }^{\circ} \mathrm{C}$, the partial orientation in the films was clearly observed. The degree of orientation is more significant for SA copolymer than for LA copolymer, consistent with the mechanical properties.
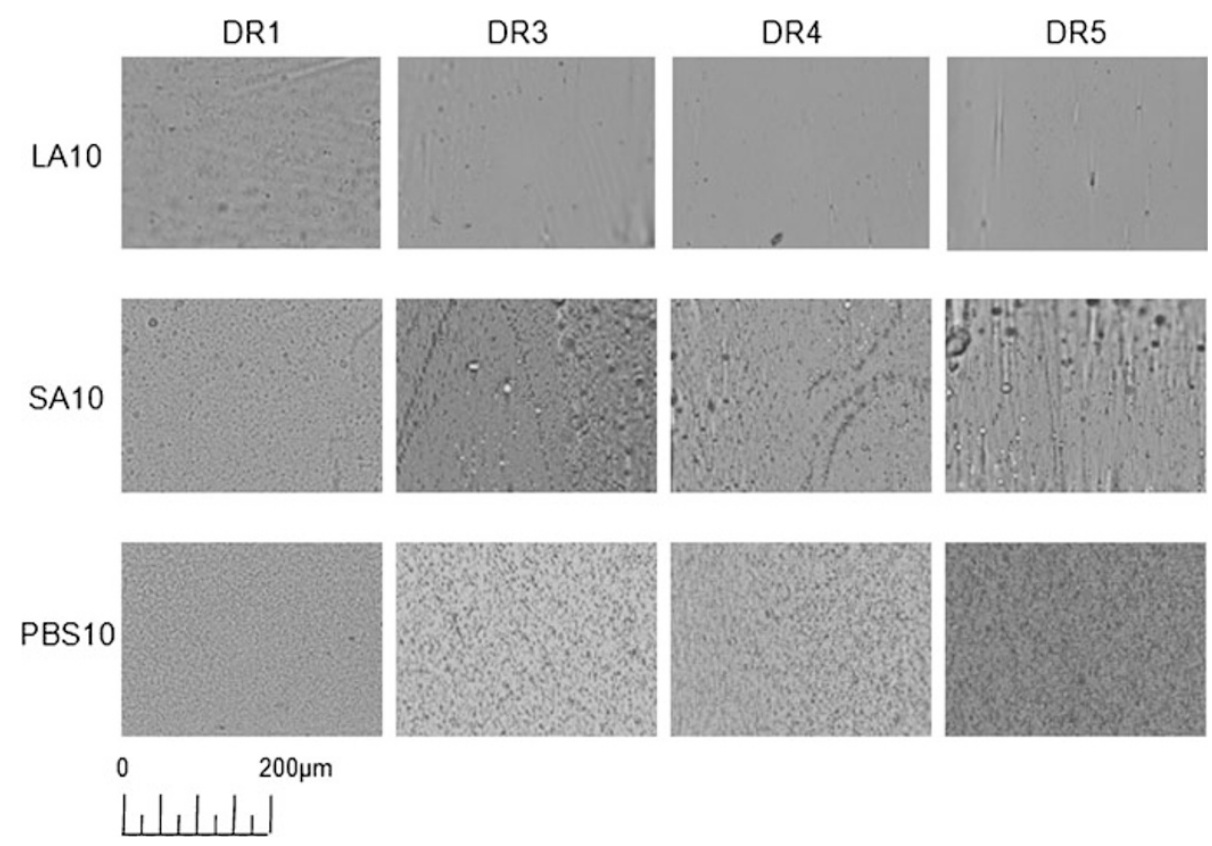

Figure 7. Optical microscopy images of the blend films of PLLA and additive polymers at different draw ratios. 


\section{CONCLUSION}

The mechanical properties of the blend films of PLLA and PDC polyesters were studied by tensile measurements. SA copolymer was found to be a better additive than LA copolymer, because of the superior crystalline feature and excellent miscibility with PLLA. Thus, the highest tensile strength at break was $128 \mathrm{MPa}$ for SA2.5 with $\mathrm{DR}=5$. In contrast to PBS, which dramatically decreased viscoelastic features of the blend films, SA copolymer could also improve the elongation at break. The highest fracture strain $148 \%$ was recorded for SA7.5 with $\mathrm{DR}=1$. The degree of crystallinity determined by X-ray diffraction analysis did not show the difference in the molecular orientation, whereas optical microscopy images clarified the partial orientation by addition of SA copolymer and drawing. Combined with the recently reported biodegradability of the blend films, ${ }^{38}$ PDC polyesters are useful biomass-based polymers for construction of carbonneutral sustainable society.

Acknowledgment. This work was supported, in part, by a Grant-in-Aid for Scientific Research from the Ministry of Education, Science, Sports and Culture, Japan, and General Sekiyu Research Promotion. We thank Prof. S. Kajita (Tokyo University of Agriculture and Technology) for useful discussion.

Received: June 1, 2009

Accepted: June 25, 2009

Published: August 5, 2009

\section{REFERENCES}

1. "Biopolymers," A. Steinbuchel, Y. Doi, and M. Hofrichter, Ed., Wiley-VCH, Weinheim, 2002, Vol. 3.

2. T. Iwata and Y. Doi, Macromol. Chem. Phys., 200, 2429 (1999).

3. A. K. Agrawal and R. Bhalla, J. Macromol. Sci., Polym. Rev., C43, 479 (2003).

4. E. T. H. Vink, R. Rabago, D. A. Glassner, B. Spring, R. P. O'Connor, J. Kolstad, and P. R. Gruber, Macromol. Biosci., 4, 551 (2004).

5. H. Tsuji, Macromol. Biosci., 5, 569 (2005).

6. Y. Nishio, Adv. Polym. Sci., 205, 97 (2006).

7. J. R. Dorgan, B. Braun, J. R. Wegner, and D. M. Knauss, "Oegradable Polymers and Materials: Principles and Practice (ACS Symposium Series)", K. Khemani and C. Scholz, Ed., ACS Publication, 2006, vol. 939 p 102.

8. B. Gupta, N. Revagade, and J. Hiborn, Prog. Polym. Sci., 32, 455 (2007).

9. B.-H. Li and M.-C. Yang, Polym. Adv. Technol., 17, 439 (2006).

10. M. Todo and T. Takayama, J. Mater. Sci., 42, 4712 (2007).

11. N. Kawamoto, A. Sakai, T. Horikoshi, T. Urushihara, and E. Tobita, J. Appl. Polym. Sci., 103, 244 (2007).

12. S. Iannace, L. Ambrosio, S. J. Huang, and L. Nicolais, J. Appl. Polym.
Sci., 54, 1525 (1994).

13. E. Blümm and A. J. Owen, Polymer, 36, 4077 (1995).

14. A. Nijenhuis, E. Colstee, D. W. Grijpma, and A. J. Pennings, Polymer, 37, 5849 (1996).

15. M. Hiljanen-Vainio, P. Varpomaa, J. Seppälä, and P. Törmälä, Macromol. Chem. Phys., 197, 1503 (1996).

16. J. M. Yang, H. L. Chen, J. W. You, and J. C. Hwang, Polym. J., 29, 657 (1997).

17. M. Sheth, R. A. Kumar, V. Davé, R. A. Gross, and S. P. McCarthy, J. Appl. Polym. Sci., 66, 1495 (1997).

18. M. R. Lostocco, A. Borzacchiello, and S. J. Huang, Macromol. Symp., 130, 151 (1998).

19. J.-S. Yoon, S.-H. Oh, M.-N. Kim, I.-J. Chin, and Y.-H. Kim, Polymer, 40, 2303 (1999).

20. M. E. Broz, D. L. VanderHart, and N. R. Washburn, Biomaterials, 24, 4181 (2003).

21. Y. Hu, M. Rogunova, V. Topolkaraev, A. Hiltner, and E. Baer, Polymer, 44, 5701 (2003).

22. Y. Hu, Y. S. Hu, V. Topolkaraev, A. Hiltner, and E. Baer, Polymer, 44, 5711 (2003).

23. K. Nakane, Y. Hata, K. Morita, T. Ogihara, and N. Ogata, J. Appl. Polym. Sci., 94, 965 (2004).

24. W. Kai, L. Zhao, B. Zhu, and Y. Inoue, Macromol. Rapid Commun., 27, 109 (2006).

25. Y. Otsuka, M. Nakamura, K. Shigehara, K. Sugimura, E. Masai, S. Ohara, and Y. Katayama, Appl. Microbiol. Biotechnol., 71, 608 (2006).

26. T. Michinobu, M. Hishida, M. Sato, Y. Katayama, E. Masai, M. Nakamura, Y. Otsuka, S. Ohara, and K. Shigehara, Polym. J., 40, 68 (2008).

27. T. Michinobu, Y. Inazawa, K. Hiraki, Y. Katayama, E. Masai, M. Nakamura, S. Ohara, and K. Shigehara, Chem. Lett., 37, 154 (2008).

28. M. Hishida, K. Shikinaka, Y. Inazawa, Y. Katayama, S. Kajita, E. Masai, M. Nakamura, Y. Otsuka, S. Ohara, and K. Shigehara, Kobunshi Ronbunshu, 66, 141 (2009).

29. M. Hishida, K. Shikinaka, Y. Katayama, S. Kajita, E. Masai, M. Nakamura, Y. Otsuka, S. Ohara, and K. Shigehara, Polym. J., 41, 297 (2009).

30. T. Michinobu, M. Bito, Y. Yamada, M. Tanimura, Y. Katayama, E. Masai, M. Nakamura, Y. Otsuka, S. Ohara, and K. Shigehara, in submission.

31. T. Michinobu, M. Bito, M. Tanimura, Y. Katayama, E. Masai, M. Nakamura, Y. Otsuka, S. Ohara, and K. Shigehara, in submission.

32. M. Funaoka, Polym. Int., 47, 277 (1998).

33. T. Yoshida, R. Lu, S. Han, K. Hattori, T. Katsuta, E. Takeda, K. Sugimoto, and M. Funaoka, J. Polym. Sci., Part A: Polym. Chem., 47, 824 (2009).

34. A. J. Ragauskas, C. K. Williams, B. H. Davison, G. Britovsek, J. Cairney, C. A. Eckert, W. J. Frederick, Jr., J. P. Hallett, D. J. Leak, C. L. Liotta, J. R. Mielenz, R. Murphy, R. Templer, and T. Tschaplinski, Science, 311, 484 (2006).

35. G. Natta, P. Corradini, and M. Cesari, Accad. Naz. Lincei., 22, 11 (1957).

36. T. Michinobu, M. Bito, Y. Yamada, Y. Katayama, K. Noguchi, E. Masai, M. Nakamura, S. Ohara, and K. Shigehara, Bull. Chem. Soc. Jpn., 80, 2436 (2007).

37. J. Takagi, T. Nemoto, T. Takahashi, T. Taniguchi, and K. Koyama, Sen'i Gakkaishi, 60, 230 (2004).

38. M. Bito, T. Michinobu, Y. Katayama, Y. Otsuka, M. Nakayama, S. Ohara, E. Masai, and K. Shigehara, Trans. Mater. Res. Soc. Jpn., 33, 1165 (2008). 